\title{
Repetitive Behaviors in Monkeys Are Linked to Specific Striatal Activation Patterns
}

\author{
Esen Saka, ${ }^{1}$ Claudia Goodrich, ${ }^{2}$ Patricia Harlan, ${ }^{3}$ Bertha K. Madras, ${ }^{2}$ and Ann M. Graybiel ${ }^{3}$ \\ ${ }^{1}$ Department of Neurology, Akdeniz University Hospital, 07059 Antalya, Turkey, ${ }^{2}$ Department of Psychiatry, Harvard Medical School, New England Primate \\ Research Center, Southborough, Massachusetts 01772-9102, and ${ }^{3}$ Department of Brain and Cognitive Sciences, Massachusetts Institute of Technology, and \\ the McGovern Institute for Brain Research, Cambridge, Massachusetts 02139
}

The spontaneous behavior of humans can be altered dramatically by repeated exposure to psychomotor stimulants. We have developed a primate model for analyzing the neurobiology underlying such drug-induced behavioral changes. We performed ethogram-based behavioral assays on squirrel monkeys given single or multiple cocaine treatments, and in the same monkeys made anatomical plots of striatal neurons that were activated to express early-gene proteins. A final cocaine challenge after chronic intermittent exposure to cocaine induced highly patterned behavioral changes in the monkeys, affecting individual behavioral motifs in distinct ways. In the striatum, the challenge dose induced striosome-predominant expression combined with intense dorsal early-gene expression, especially in the putamen. These patterns of gene expression were highly predictive of the levels of stereotypy exhibited by the monkeys in response to cocaine challenge. The total levels of expression, on the other hand, appeared to reflect increased spontaneous behavioral activation during the drug-free period after the cocaine exposure. We suggest that in the primate, compartmentally and regionally specific striatal activation patterns contribute to the striatal modulation of psychostimulant-induced behaviors. These observations in nonhuman primates raise the possibility that monitoring such basal ganglia activity patterns could help to delineate the neural mechanisms underlying drug-induced repetitive behaviors and related syndromes in which stereotypies are manifest.

Key words: squirrel monkey; behavioral sensitization; cocaine; dopamine; caudate nucleus; putamen; nucleus accumbens; striatum; stereotypy; striosome; matrix

\section{Introduction}

Repetitive actions occur as a part of normal behaviors ranging from simple mannerisms to highly skilled acts acquired through practice. Such behaviors, however, can become exaggerated and behaviorally dominant in neuropsychiatric disorders including obsessive-compulsive spectrum disorders, autistic syndromes, and schizophrenia (Ridley, 1994; Leckman, 2002). Observations both in humans and in experimental animals have pointed to abnormalities in cortico-basal ganglia circuits as primary neural correlates of motor and cognitive repetitiveness (Graybiel and Rauch, 2000; Mink, 2001; Leckman, 2002).

Severe stereotypies can be induced in species ranging from rodents to humans by repeated exposure to psychomotor stimulants that directly or indirectly activate dopamine receptors (Baldessarini, 1972; Scraggs and Ridley, 1978; Segal et al., 1980; Haber et al., 1981; Robbins, 1982; Robinson and Becker, 1986;

Received Aug. 25, 2003; revised July 14, 2004; accepted July 15, 2004.

This work was funded by the National Parkinson Foundation (E.S., A.M.G.), National Institutes of Health Grants DA08037 and NS25529 (A.M.G.), the Stanley Foundation (A.M.G.), and Grants DA06303, DA15305, DA11558, and RR00168 (B.K.M.). We thank Drs. Juan Canales and Magdalena Sauvage for critical discussion; Michele Boyd, Mary Beth Manjerovic, and Christina Barr for technical assistance; Dr. Rodrigo Bravo for his kind gift of the JunB antiserum; and H. F. Hall for his help and for photography.

Correspondence should be addressed to Dr. Ann M. Graybiel, Department of Brain and Cognitive Sciences, Massachusetts Institute of Technology and the McGovern Institute for Brain Research, 45 Carleton Street, E25-618, Cambridge, MA 02139. E-mail: graybie@@mit. edu.

DOI:10.1523/JNEUROSCI.1072-04.2004

Copyright $\odot 2004$ Society for Neuroscience $\quad$ 0270-6474/04/247557-09\$15.00/0
Walters et al., 1987; Farfel et al., 1992; Kalivas et al., 1993; Rosenzweig-Lipson et al., 1994; Gawin and Khalsa-Denison, 1996; Sams-Dodd and Newman, 1997; Canales and Graybiel, 2000; Capper-Loup et al., 2002; Saka et al., 2002). The rodent models of stereotypic behavior have been used for studying the neural basis of disorders manifesting repetitive behaviors. These models are based on the fact that repeated intermittent administration of combined D1-D2 dopamine receptor agonists to rats leads to behavioral sensitization, a state in which, even after a period of drug abstinence, additional drug exposure can induce exaggerated activity and stereotypic behaviors (Kalivas et al., 1993). Molecular changes in dopamine, other biogenic amine and glutamate neurotransmission systems, and selective neuronal gene-activation patterns result from such drug treatments (Baldessarini, 1972; Robinson and Becker, 1986; Kalivas and Stewart, 1991; LaHoste et al., 1993; Pierce and Kalivas, 1997; Badiani et al., 1998; Mathieu-Kia and Besson, 1998; Hurd et al., 1999; Nestler et al., 1999; Graybiel et al., 2000; Bibb et al., 2001; Nestler, 2001; Willuhn et al., 2003). In addition, circuit-level neuroplasticity in cortico-basal ganglia circuits may contribute to the behavioral changes induced by repeated drug exposure in rodents, including differential activation of the striosomal system of the striatum (Canales and Graybiel, 2000; Capper-Loup et al., 2002).

The possible translation of such circuit-level findings to repetitive behavioral syndromes in primates has remained difficult to 
judge, principally because studies combining neural and behavioral assays of responses to drugs inducing stereotypy in monkeys are rare (Farfel et al., 1992; Castner and Goldman-Rakic, 1999; Porrino et al., 2002). This is an important issue to address because primate behaviors are complex, and the striatum and corresponding cortico-basal ganglia loop systems in primates are highly differentiated compared with those in rodents. We therefore performed experiments in squirrel monkeys to document the patterns of behavioral stereotypy induced by repeated cocaine exposure and to determine whether anatomical maps of earlygene activation by this psychomotor stimulant would be predictive of the stereotypic behaviors induced. We found that earlygene expression patterns in the striatum of the monkeys were remarkably sensitive indicators of previous exposure to cocaine and that striosome-predominant and dorsal early-gene expression patterns predicted with high accuracy the levels of behavioral stereotypy exhibited by the monkeys in response to cocaine challenge.

\section{Materials and Methods}

Drug treatments. Observations were made on 12 squirrel monkeys (6 females, 6 males) housed in pairs at the New England Primate Research Center under a $12 \mathrm{hr}$ light/dark cycle. Animal care and treatment were supervised by veterinarians under the guidelines and in accordance with the Institute of Laboratory Animal Resources Guide for the Care and Use of Laboratory Animals (1996). An animal care protocol was approved by the Harvard Animal Care Committee and was in compliance with the Harvard Medical School animal management program, an institution accredited by the American Association for the Accreditation of Laboratory Animal Care.

The monkeys had no previous history of drug treatment, appeared normal, and had been maintained for 3-7 years and monitored daily for this period. Two monkeys had received saline injections 3 months before the present study. Monkeys were recruited randomly into the treatment groups and were videotaped in their home cages from $\sim 9: 00$ to 11:00 A.M. for the $5 \mathrm{~d}$ preceding onset of the experiment to obtain baseline activity measures. Each monkey received a single intramuscular injection of either cocaine (cocaine $\mathrm{HCl} ; 6 \mathrm{mg} / \mathrm{kg} ; n=6$; National Institutes of Health, Bethesda, MD) or $0.9 \%$ saline $(n=6)$ once a day ( $~ 8: 00$ A.M. $)$ in its home cage for 16 consecutive days. The behavior of each monkey was recorded on videotape for $2 \mathrm{hr}$ after each injection. At the end of the treatment period, all monkeys were given a $7 \mathrm{~d}$ injection-free period of abstinence and then given a single challenge injection of either cocaine (6 $\mathrm{mg} / \mathrm{kg}$ ) or saline in their home cages and again videotaped for $2 \mathrm{hr}$.

Three treatment protocols were followed: chronic intermittent cocaine followed by cocaine challenge ("chronic cocaine" group; $n=6$ ), chronic intermittent saline treatment followed by cocaine challenge ("acute cocaine" group; $n=4$ ), and chronic intermittent saline followed by saline challenge ("chronic saline" group; $n=2$ ). For practical reasons and to maintain uniformity of treatment schedules, the monkeys were divided into three smaller groups for concurrent treatment, with each subgroup including acute and chronic treatments. We did not include an experimental group in which monkeys were treated repeatedly with cocaine and then challenged with saline, as usually included in studies in rodents (Hope et al., 1992; Canales and Graybiel, 2000), because Fos induction was found to be minimal in such studies. Preliminary experiments leading to those reported here did indicate that saline injection was a relatively ineffective conditioning agent for inducing Fos induction patterns, even after cocaine response (data not shown).

Behavioral analyses. For behavioral analysis, the videotapes were scored independently by a minimum of two to four observers, of whom at least one was blinded to the treatment type. Inter-rater reliability generally exceeded $90 \%$ after a period of training. The rating scale shown in Table 1 was used to estimate the expression of stereotyped behaviors. The scale was based on an ethogram analysis of individual behavioral motifs developed after repeated observation of the tapes and by adapting rating scales previously developed for the analysis of cocaine-induced behaviors in monkeys (Post et al., 1976; Miczek and Yoshimura, 1982; Farfel et al., 1992; Rosenzweig-Lipson et al., 1994). In developing the scale, the intensity, length of time, and frequency of occurrence of individual behaviors were assessed, and an ethogram analysis, based on initial analysis of the behaviors observed, was developed to focus on five behavioral motifs that were clearly affected by the drug treatments: head swinging, huddling, spatial confinement, visual tracking, and repetitive postural shifts, as shown in Table 1. The behavior of each monkey was rated for 2 min every $3 \mathrm{~min}$ from 10 to $60 \mathrm{~min}$ after treatment. Each behavioral motif was given a score of 0,1 , or 2 except for spatial confinement, which was assigned values of 0 or 1 . Scores were based on 10 ratings of individual behavior in the first hour of treatment (50 ratings for composite scores, yielding overall stereotypy scores from 0 to 9 ). Scores for monkeys in different treatment groups were compared statistically with the Tukey-Kramer multiple comparison test.

Anatomical analyses. Two hours after the final cocaine or saline challenge injection, monkeys were deeply anesthetized with pentobarbital $(50 \mathrm{mg} / \mathrm{kg})$ and perfused transcardially with $0.9 \%$ saline, $4 \%$ paraformaldehyde, and $5 \%$ sucrose in $0.1 \mathrm{M} \mathrm{NaKPO}_{4}$ buffer and $5 \%$ sucrose in $0.9 \%$ saline. The right half of each brain was analyzed for this report. Frozen transverse $30-\mu \mathrm{m}$-thick sections cut on a sliding microtome were stained free-floatingly by single- or dual-antigen immunohistochemical methods for Fos and/or JunB, striatal cellular markers, striosomal markers, or Fos-marker combinations (Graybiel and Chesselet, 1984; Saka et al., 2002). To mark early-gene responses to the final drug challenges, sections were treated with rabbit polyclonal anti-c-Fos (Ab-5; 1:40,000; Calbiochem, La Jolla, CA) and anti-JunB (1:10,000; kind gift from R. Bravo, Bristol-Myers Squibb, Wallingford, CT). To identify striosome and matrix compartments, we used rabbit polyclonal anti-met-enkephalin (1: 2000; Diasorin, Stillwater, MN) and mouse monoclonal parvalbumin antibody (1:1000; Sigma, St. Louis, MO). Striatal interneurons were stained with goat anti-choline acetyltransferase (ChAT) (1:2000; Chemicon, Temecula, CA), rabbit anti-calretinin (1:4000; Swant, Bellinzona, Switzerland), and mouse anti-parvalbumin antibodies and with NADPH-diaphorase histochemistry. Dual-antigen immunostaining was performed for Fos and each immunomarker according to Saka et al. (2002) with the ABC method (Vector Laboratories, Burlingame, CA). For dual-antigen staining we used diaminobenzidine (ChAT, calretinin, parvalbumin) and nickel ammonium-enhanced diaminobenzidine (cFos, JunB).

Data analysis. Sections were evaluated by light microscopy, and because the patterns of immunostaining obtained with the Fos and JunB antisera were similar and the Fos-stained material had lower background staining levels, quantitative analyses were performed on Fosimmunostained sections. Fos-positive nuclei in the caudate nucleus, putamen, and ventral striatum were charted for an anterior section $(A=15)$ and a mid-anteroposterior section $(\mathrm{A}=13)$ with a computerized imaging system (Biocom, Les Ulis, France). The borders of striosomes were drawn from serially adjacent sections stained for enkephalin and parvalbumin, and the outlines of striosomes that were identified with either or both immunostains were merged with the chart of Fos immunostaining using local blood vessels as fiducial landmarks. In the most ventral parts of the striatum, differentiation of striosomes became unclear, and these regions were excluded from the quantitative analysis. The densities of Fos-immunoreactive neurons in striosomes and the extrastriosomal matrix were calculated on the basis of the merged charts, and the ratio of these densities was defined as an index of striosome-to-matrix predominance (ISMP ratio). The densities of Fos-immunostained neurons in the caudate nucleus and in the putamen were also calculated separately, as well as the densities of Fos-positive neurons in the dorsal and ventral parts of these regions. These dorsoventral zones were defined individually for each monkey by including within the dorsal zone the region that, in that individual, had dense, nearly homogenous Fos expression. This region corresponded to approximately the dorsal third of the caudate nucleus and putamen. In the monkeys in which such dense dorsal labeling was not detectable, we included the dorsal one-third of the caudate nucleus and putamen in the dorsal zone. Fos-immunoreactive interneurons were plotted in a separate series of charts.

The Fos expression data for monkeys treated by different protocols 
Table 1. Ethogram analysis of individual stereotypic behaviors

\begin{tabular}{|c|c|c|c|}
\hline Observed behavior & Definition of behavior & Scores & Definition of score \\
\hline \multirow[t]{3}{*}{ Head swinging } & \multirow{3}{*}{$\begin{array}{l}\text { Rapid side-to-side head movements } \\
\text { with little or no postural adjustment } \\
\text { and with no apparent relation to } \\
\text { purposeful activity }\end{array}$} & 0 & 0ccurs fewer than five times in $2 \mathrm{~min}$ \\
\hline & & 1 & 0 ccurs for a period of $30-90 \mathrm{sec}$ in $2 \mathrm{~min}$ \\
\hline & & 2 & Occurs repeatedly and consistently \\
\hline \multirow[t]{3}{*}{ Huddling } & \multirow{3}{*}{$\begin{array}{l}\text { Stationary body position with slumped } \\
\text { posture }\end{array}$} & 0 & 0 ccurs for $<30 \sec$ in $2 \min$ \\
\hline & & 1 & $\begin{array}{l}\text { Accompanying stereotypic head } \\
\text { movements }\end{array}$ \\
\hline & & 2 & $\begin{array}{l}\text { 0ccurs for }>90 \text { sec in } 2 \text { min and with } \\
\text { accompanying stereotypic head } \\
\text { movements }\end{array}$ \\
\hline \multirow[t]{2}{*}{ Spatial confinement } & \multirow{2}{*}{$\begin{array}{l}\text { Normal posture with little or no } \\
\text { movement of head or body }\end{array}$} & 0 & Present \\
\hline & & 1 & Absent \\
\hline \multirow[t]{3}{*}{ Visual tracking } & \multirow{3}{*}{$\begin{array}{l}\text { Hypervigilant state consisting of head } \\
\text { movements to sustain visual } \\
\text { scanning with no apparent relation } \\
\text { to purposeful activity }\end{array}$} & 0 & 0 ccurs $<30$ sec in 2 min \\
\hline & & 1 & 0ccurs for $30-90$ sec in 2 min \\
\hline & & 2 & Occurs repeatedly and consistently \\
\hline \multirow[t]{3}{*}{ Repetitive postural shifts } & \multirow{3}{*}{$\begin{array}{l}\text { Repetitive grasping of wire mesh and } \\
\text { shifting of posture with no steps } \\
\text { taken and no apparent relation to } \\
\text { purposeful behavior }\end{array}$} & 0 & Occurs no more than twice in $2 \mathrm{~min}$ \\
\hline & & 1 & 0ccurs three or more times in $2 \mathrm{~min}$ \\
\hline & & 2 & $\begin{array}{l}\text { Consistent, repetitive motions while } \\
\text { stationary }\end{array}$ \\
\hline
\end{tabular}

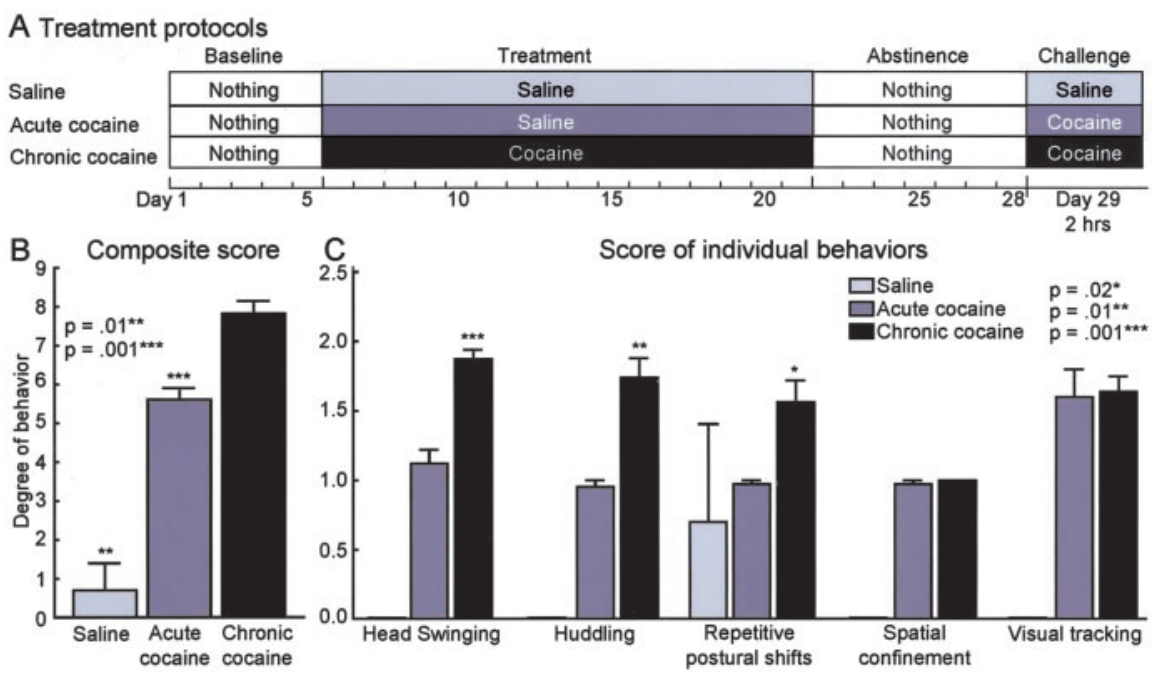

Figure 1. Squirrel monkeys exhibit a range of stereotypic behaviors in response to cocaine exposure. $A$, Treatment protocols for the monkeys of the saline, acute cocaine, and chronic cocaine groups. B, Bar graphs illustrate the level of stereotypy expressed in monkeys of the chronic saline, acute cocaine, and chronic cocaine groups, as determined by ethogram analysis (Table 1). Asterisks indicate significance values for the stereotypy scores of monkeys of the chronic saline group $\left({ }^{* *} p=0.01\right)$ and the acute cocaine group $\left({ }^{* *} p=0.001\right)$ relative to the stereotypy scores for monkeys of the chronic cocaine group. C, Bar graphs illustrate the levels of individual behaviors exhibited by monkeys of the saline, acute cocaine, and chronic cocaine groups. Asterisks indicate significance values for the individual behavioral scores for the chronic cocaine group relative to the scores for the acute cocaine group.

were compared by means of Kruskal-Wallis and Mann-Whitney $U$ tests. The anatomical and behavioral data were compared by computing correlations between stereotypy scores and scores for the early-gene data. For the anatomical analyses, measurements included the density of Fospositive neurons in striosomes, extrastriosomal matrix, caudate nucleus, putamen, dorsal and ventral parts of the caudate nucleus and putamen, and the caudate nucleus and putamen in combination.

\section{Results}

Behavioral stereotypies induced by chronic intermittent and acute exposure to cocaine

The cage behaviors of the three groups of monkeys were readily distinguishable by observers blinded to the treatment type. Monkeys in the chronic cocaine group exhibited striking stereotypic behaviors in response to the final cocaine challenge. These in- cluded rapid side-to-side swinging movements of the head interrupted by brief periods of visual tracking or staring (frequently at a raised hand) and huddling either in a corner or at the bottom of the cage. Other behaviors included cage clutching and holding, to-and-fro rocking, and swinging. Each monkey exhibited an individually distinct pattern of behavior, but all of the monkeys exhibited profoundly repetitive individual movement motifs together with a sharp reduction in locomotion and general movements about the cage and a decline in distractibility. Their average score on the ethogrambased rating scale was $7.8 \pm 0.3$, with a range from 8.8 to 6.5 (Table 1). Monkeys in the acute cocaine group displayed similar patterns of behavior, but side-to-side head swings and huddling were less prominent, the individual stereotypic movements were repeated less often, the monkeys were more distractible, and they moved more frequently in the cage, albeit in a compulsive manner. Their average stereotypy scores were lower than those of the chronic cocaine group (mean, $5.6 \pm$ 0.3 ; range, $5.0-6.3$ ). Monkeys treated only with saline (chronic saline group) spent time climbing and swinging, moved freely around the cage, looked about, and were easily distracted by the behavior of other monkeys or caretakers (mean score, $0.7 \pm$ 0.7 ). The overall behavioral stereotypy scores of monkeys in the chronic cocaine group were significantly higher than both those of the acute cocaine and those of the saline-only groups (Tukey-Kramer multiple comparison test; $p<0.001$ and $p<$ 0.01 , respectively) (Fig. 1). In turn, the overall stereotypy scores for the acute cocaine group were significantly higher than those for the saline-treated group ( $p<$ 0.001). As shown in Figure 1, the individual scores for three of the five motifs (head swinging, huddling, and repetitive postural shifts) were significantly greater for the chronically treated monkeys than those for the acutely treated monkeys $(p<0.001, p<0.01$, and $p<0.02$, respectively).

\section{Cocaine-induced patterns of Fos-Jun protein expression}

There were striking differences in the patterns of early-gene expression induced by the final challenge treatment in the three groups of monkeys. In the saline controls treated and challenged with saline, only diffusely scattered Fos-positive neurons appeared (average density, $\sim 7 / \mathrm{mm}^{2}$ ) (Figs. $2 A, 3 A$ ). In the acute cocaine group treated with saline but challenged with cocaine after the abstinence period, there was a $>20$-fold increase in Fos expression over the saline control levels $\left(\sim 170 / \mathrm{mm}^{2}\right)$. Fospositive nuclei appeared broadly through both the caudate nucleus and the putamen (Figs. $2 B, 3 B$ ). There was a slight preponderance of expression in striosomes of the caudate nucleus 

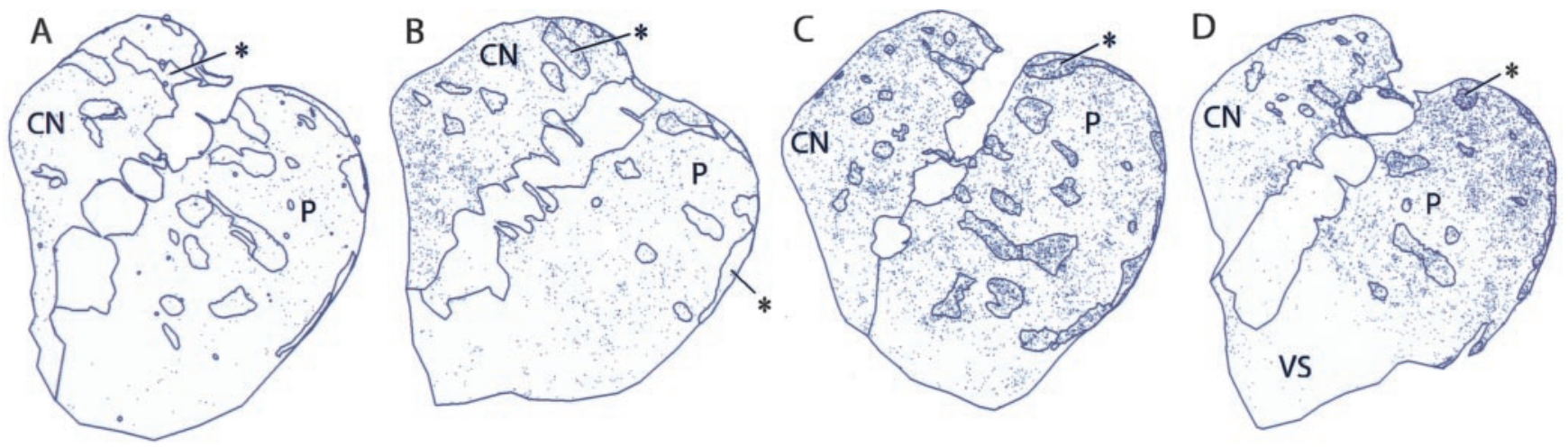

Figure 2. A single dose of cocaine induces early-gene expression in the squirrel monkey caudate nucleus $(\mathrm{CN})$ and putamen $(\mathrm{P})$, and repeated daily doses shift the expression pattern toward one of striosome predominance and accentuated dorsal expression. Illustrations indicate Fos-positive striatal neurons as small black dots. Asterisks indicate examples of striosomes, which are shown in outline. $A$, Monkey M4, chronic saline group; $B$, monkey M7, acute cocaine group; C, monkey M3, chronic cocaine group; and D, monkey M5, chronic cocaine group. Note in C the striosome-predominant patterns of Fos expression and in $D$ the dorsal cap of strong labeling together with heightened striosomal labeling. Illustrations also show low levels of Fos expression in ventral striatum (VS).

relative to expression levels in the matrix (average ISMP value, 1.78) and only a hint of striosome predominance in the putamen (average ISMP value, 1.32). Thus, a single cocaine challenge had a major effect on increasing Fos expression throughout the caudate nucleus and putamen. The expression patterns of Fos and JunB were qualitatively similar, and both early-gene products were found in medium-sized striatal neurons. Only rare interneurons expressed either gene product, as shown for Fos in Table 2.

A major redistribution of Fos expression on challenge appeared as a consequence of the repeated daily injection of cocaine (chronic cocaine group) relative to the pattern observed after repeated daily injection of saline before the final cocaine challenge (acute cocaine group). First, there was an obvious difference in the relative expression of Fos and JunB in striosomes and matrix so that expression levels in striosomes exceeded that in the matrix in the chronic cocaine group (Figs. 2-4). In the chronic group, the striosome predominance values calculated from the Fos-stained material for the putamen were two times greater than those for the acute cocaine group ( $2.64 \mathrm{vs} 1.34$ ), and the ISMP values for the caudate nucleus were a third again larger in the chronic group than in the acute group (2.26 vs 1.78). The striosome predominance appeared to result mainly from higher levels of expression in striosomes of the chronically treated monkeys (density values were $164 \pm$ 69 for the acute cocaine matrix, $136 \pm 18$ for the chronic cocaine matrix, $232 \pm 85$ for the acute cocaine striosomes, and $326 \pm 85$ for the chronic cocaine striosomes).

The second striking pattern in the chronic cocaine group was an intense expression of the early genes in the dorsal part of the striatum and especially in the dorsal putamen (Figs. 2, 3, 5A,B). This pattern was particularly marked in four of the six chronically treated monkeys, affecting either mainly the dorsal part of the putamen or both the putamen and caudate nucleus across both striosome and matrix compartments. Such elevated dorsal earlygene expression was only slight (monkey M13) or not evident
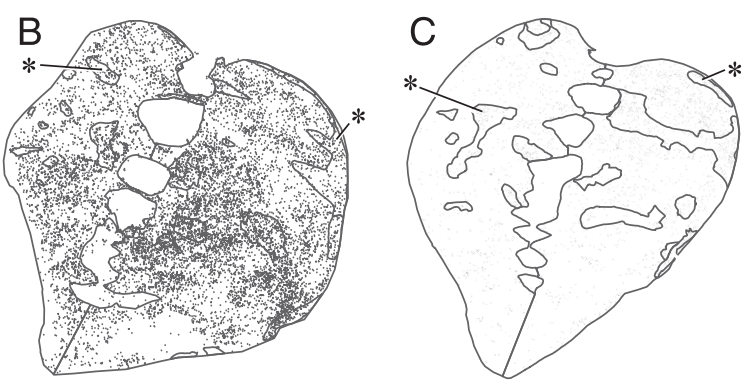

Figure 3. Cocaine-induced patterns of Fos expression in rostral striatum differ for squirrel monkeys given saline, acute cocaine, or acute and repeated exposures to the cocaine before challenge. $A$, Low density of Fos-positive neurons (black dots) in rostral striatum of squirrel monkey M4, treated with saline; $B$, higher density of Fos-positive neurons in monkey $M 9$, treated with single and far dorsal putamen in monkey M5, from the chronic cocaine group ( $16 \mathrm{~d}$ cocaine, 1 week abstinence period, final cocaine

Table 2. Estimated densities (in neurons per square millimeter) of Fos-positive neurons in striatal medium-sized neurons and in two phenotypically identified types of striatal interneuron

\begin{tabular}{llll}
\hline Group & $\begin{array}{l}\text { Medium-sized } \\
\text { neurons }^{a}\end{array}$ & $\begin{array}{l}\text { Somatostatinergic } \\
\text { (NADPH diaphorase-positive) neurons }\end{array}$ & $\begin{array}{l}\text { Cholinergic } \\
\text { (ChAT-positive) neurons }\end{array}$ \\
\hline Acute cocaine & $172.21 \pm 70.75$ & $0.87 \pm 0.45$ & $0.18 \pm 0.06$ \\
Chronic cocaine & $162.01 \pm 17.09$ & $2.01 \pm 0.82$ & $0.19 \pm 0.03$ \\
\hline
\end{tabular}

${ }^{a}$ Stains for four of the known classes of striatal interneuron (positive for NADPH diaphorase reactive or immunoreactive for ChAT, calretinin, or parvalbumin) were used to identify striatal interneurons. No calretinin- or parvalbumin-positive neurons were found to be Fos-positive. Medium-sized Fos-positive neurons were calculated from sections single-stained for Fos. Note that values for NADPH diaphorase- and ChAT-positive interneurons are very small and lie within the SEM values for the medium-sized neuron counts.

(M3) in the two remaining monkeys of the chronic group. A dorsal elevation in levels of expression did not occur in any monkeys of the acute cocaine group except one (M12), and in this monkey, the dorsal elevation occurred only at far-rostral levels, levels anterior to those used for quantitative analysis.

In view of this dorsoventral difference in striatal activation in the chronically treated monkeys, we performed a third analysis by examining Fos densities in the dorsal and ventral parts of the striatal zones charted and also calculating these separately for the caudate nucleus and putamen. The results indicated very high striosomal predominance in the ventral zones, especially in the putamen, in the chronically treated monkeys. The average ventral ISMP values were 2.9 for the putamen and 2.5 for the caudate nucleus in the chronic cocaine group, compared with ventral ISMP values of 1.3 and 1.5 in the acute cocaine group $(p<0.05)$. Taking all measurements together, the most typical pattern in the 

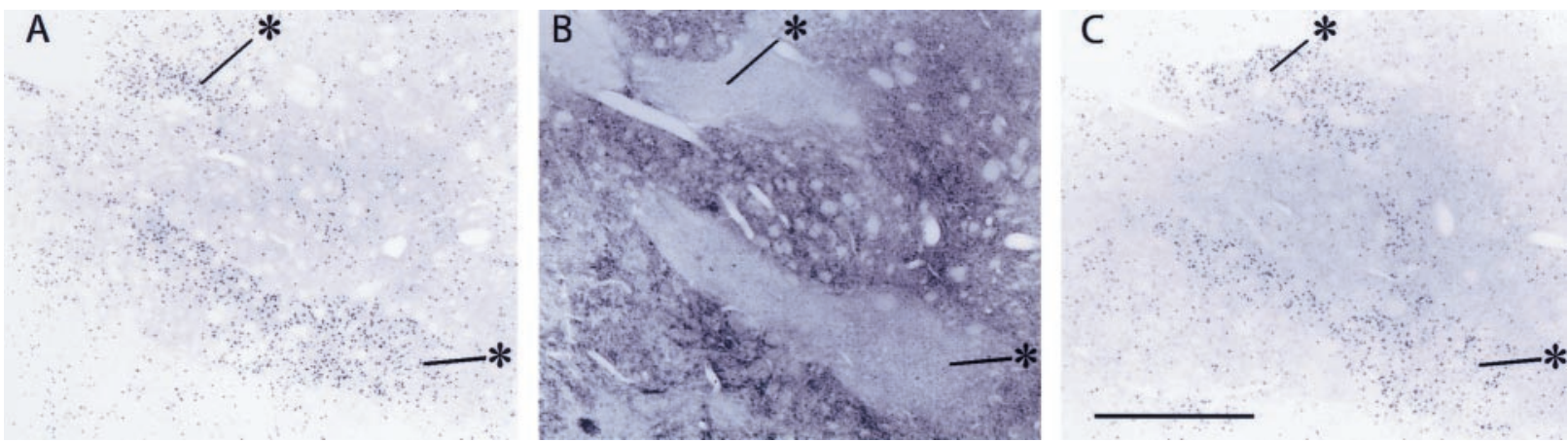

Figure 4. Heightened striosomal distributions of early-gene products Fos and JunB occur in the striatum of squirrel monkeys given a cocaine challenge after repeated daily cocaine treatments and drug abstinence. Photomicrographs illustrate serially adjacent sections immunostained for Fos-like immunoreactivity $(A)$, enkephalin-like immunoreactivity $(B)$, and JunB-like immunoreactivity (C). Striosomes are identifiable as enkephalin-poor zones (examples shown by asterisks). Scale bar, $1 \mathrm{~mm}$.

chronically treated monkeys was one in which dense dorsal to dorsolateral activation was combined with highly striosomepredominant activation farther ventrally and more moderate striosome predominance elsewhere.

In contrast to the consistency with which these patterns of striatal early-gene expression distinguished the acute and chronic cocaine treatment groups on final cocaine challenge, the total density of Fos induction in response to cocaine challenge varied from monkey to monkey. There were up to sixfold differences in the density of challenge-induced Fos-positive neurons within the individual cocaine treatment groups (Table 3). Nevertheless, across the different intensity levels, it was the differential Fos distribution patterns that were reflective of the cocaine treatment given before the challenge. For the monkeys with strong earlygene expression in the striatum, ISMP values were 1.5 times as high for the chronic cocaine group as for the acutely treated monkeys (averages, 2.08 for chronic; 1.32 for acute), and for the monkeys with weaker striatal expression, the ISMP values of the chronic group were nearly twice as high (averages, 3.46 for chronic; 1.93 for acute).

Analysis of the ventral striatum-nucleus accumbens region showed that Fos expression levels were not elevated by the repeated cocaine treatments before challenge relative to those of the acutely treated monkeys. The densities were actually lower in the chronic cocaine group than in the acute cocaine group $(p<0.02)$ (Figs. 2, 3, 5C).

\section{Activation patterns predictive of behavioral repetitiveness}

There was a clear and strong correlation between these differential anatomical patterns of cocaine-induced Fos expression and
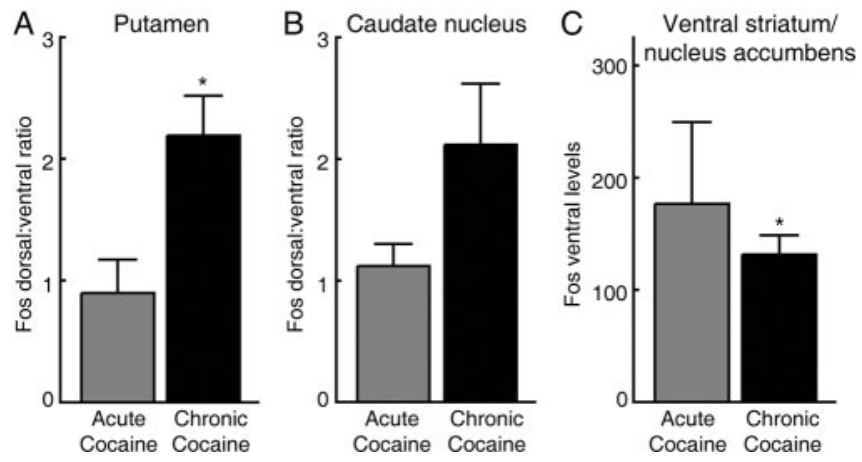

Figure 5. Fos expression patterns in the striatum shift after repeated cocaine treatment relative to patterns in acute cocaine group. $A$, Dorsal to ventral Fos expression ratio in the putamen. $B$, Dorsal to ventral Fos expression in the caudate nucleus. $C$, Fos expression in the nucleus accumbens. Asterisk indicates significance level of $p \leq 0.02$ the levels of stereotypy exhibited by the monkeys after the challenge (Fig. 6). The Spearman $r$ value for the relationship between striosomal Fos densities and the general stereotypy scores was $0.83(p=0.001)$ for the caudate nucleus, 0.71 ( $p=0.009)$ for the putamen, and $0.71(p=0.009)$ for the striatum as a whole (Fig. $6 A)$. The correlations for ISMP values were almost as high as those for striosomes $(r=0.63,0.66$, and 0.79 , respectively, for the caudate nucleus, putamen, and striatum, with corresponding $p$ values $0.03,0.02$, and 0.002 ). In contrast, matrix densities showed much lower and statistically insignificant correlations $(r=0.42$, 0.45 , and 0.43 for the caudate nucleus, putamen, and striatum, respectively, with $p$ values $0.18,0.15$, and 0.17 ) (Fig. $6 B$ ). The overall levels of Fos induction were also not correlated with the severity of stereotypy (for the caudate nucleus, $r=0.43, p=0.17$; for the putamen, $r=0.49, p=0.10$; and for the entire caudateputamen, $r=0.48, p=0.11$ ).

The degree to which the final challenge dose activated Fos expression in the dorsal zone of the putamen was also highly predictive of the overall levels of stereotypy exhibited by the monkeys in response to challenge. The Spearman $r$ values were 0.71 $(p=0.009)$ for the putamen and $0.63(p=0.03)$ for the striatum as a whole (Fig. 6C). Values for the caudate nucleus were not significant. The striosome predominance and dorsal caudateputamen activation patterns selectively predicted the occurrence of each of three of the main behaviors that we monitored: head swing, huddling, and visual tracking $(p<0.05)$.

\section{Spontaneous behavior during the post-treatment abstinence period and Fos expression levels}

In contrast to the patterns of Fos expression, the total density of Fos expression in the striatum was not correlated with the levels of stereotypy exhibited by the monkeys after final cocaine challenge. The total Fos expression levels did appear to reflect the general levels of behavioral activation exhibited by the monkeys during the week-long injection-free period after cocaine exposure. We calculated composite stereotypy scores for $5 \mathrm{~d}$ of the post-treatment period of all the monkeys treated with either chronic saline, acute cocaine, or chronic cocaine and performed Spearman regression analyses with the values for Fos expression after challenge. This analysis showed that the density of Fospositive neurons in the caudate nucleus $(r=0.72 ; p=0.008)$ (Fig. 7A), dorsal putamen $(r=0.66 ; p=0.02)$, and dorsal striatum as a whole $(r=0.70 ; p=0.01)$ reflected the spontaneous stereotypies exhibited during the period of abstinence. The abstinence-period stereotypy scores of monkeys with strong Fos expression were more than two times higher than those of the monkeys with lower levels of Fos expression. This correlation did 
reflect the treatments, because we found no correlation between Fos expression and the baseline stereotypy scores during the $5 \mathrm{~d}$ before treatment began (Fig. $7 B$ ).

\section{Discussion}

Repeated exposure to cocaine produced striking repetitive behaviors in squirrel monkeys again exposed to the drug, with each monkey expressing one or more behavioral motifs in a highly stereotyped manner. Monkeys exposed only once to cocaine exhibited mild but equally individualistic stereotypies. Yet, despite the differing content of the stereotypic behaviors exhibited in response to cocaine challenge (for example, head swinging, visual tracking, and huddling), early-gene assays of neuronal activity in the striatum provided neuronal markers reliably correlated with the presence and strength of overall stereotypic behavior evoked by the challenge dose of cocaine.

The single pattern of early-gene expression most predictive of the levels of behavioral stereotypy after challenge was an overall predominance of the gene expression in striosomes. The high correlation suggests that repetitive stereotypic behaviors induced in primates by cocaine are differentially affected by striosome-based neural circuits or at least are associated with activation of these circuits. A second gene-based activation pattern that predicted the stereotypy levels after challenge was the presence of a dense band of Fos expression in the dorsal zone of the putamen. These patterns of striosome predominance and dorsal labeling may be related, given that the highest levels of striosome predominance were typically in the ventral half to two-thirds of the putamen, below a dorsal region of near-homogeneous dense labeling.

It is unlikely that generalized challenge-induced early-gene expression, rather than patterned early-gene responses in particular striatal circuits, led to the correlations that we observed between the stereotypies and the Fos patterns. High total numbers of striatal neurons expressing Fos-Jun proteins did occur in some monkeys expressing relatively low levels of stereotypy in response to challenge, and very low levels of striatal Fos-Jun expression occurred in some monkeys exhibiting high levels of stereotypy in response to challenge. We did note, however, some relationship between the overall density of Fos-positive striatal neurons and the levels of spontaneous stereotypic behavior during the period of post-treatment abstinence before final challenge. If borne out by additional studies, this observation would indicate that an increased general inducibility of Fos-Jun proteins in the striatum can occur in relation to an increase in spontaneous, nondrug-induced behavior after cocaine exposure and that this could form a background for such differential anatomical expression patterns as we observed here.

Our findings suggest a neural correlate of stereotypy in the primate. This possibility has two important implications. First, our observations suggest that the neural mechanisms controlling which behavioral acts are performed can be distinguished from neural mechanisms controlling the intensity of expression of these behavioral acts. The monkeys' behaviors were idiosyncratic,
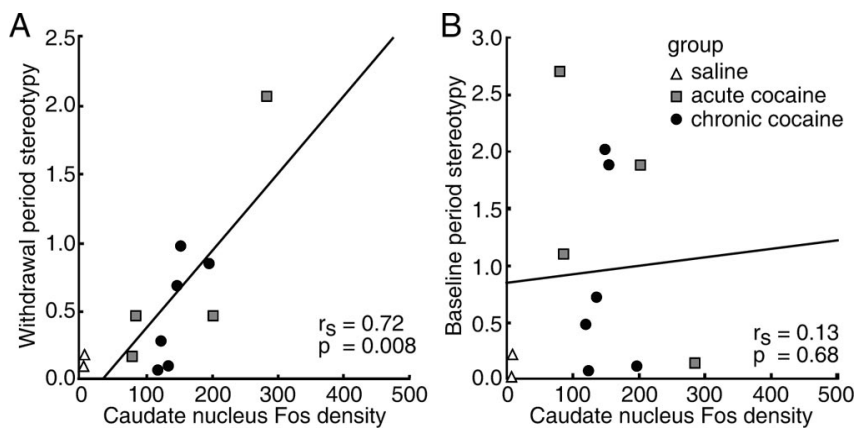

Figure 7. Total density of Fos-positive neurons in the caudate nucleus of the squirrel monkey is correlated with the levels of spontaneous stereotypic behavior exhibited after treatment during the drug-free period of abstinence $(A)$ but not with the baseline activity of monkeys before treatment $(B)$. The graphs show regression analyses of the behavioral scores ( $y$-axes) in relation to the density of Fos expression in the caudate nucleus ( $x$-axes).

so that different behaviors could be exhibited at lower or higher levels of intensity in different monkeys. The principal effect of the repeated cocaine exposures was to increase the frequency and vigor with which particular behaviors were performed rather than to change the panel of behaviors performed. Recognizing this distinction should open new ways to study the neural origins of stereotypies, at least those that are induced by psychomotor stimulants.

Second, because our results were based on linking detailed analysis of behavior with a population-level analysis of neural activity, at least as reflected by early-gene induction, they suggest a new primate model for the analysis of clinical syndromes marked by stereotypies and other repetitive behaviors. In the 
treatment of such disorders, dopaminergic and serotonergic systems are targeted. Our findings suggest that changes in these neurotransmitter systems could affect the development of repetitive behaviors by differentially affecting neural systems linked to the striosome and matrix compartments of the striatum and more dorsal versus more ventral parts of the caudate-putamen complex. For example, D1- and D2-class dopamine receptors and the dopamine transporter have unequal distributions in striosome and matrix compartments and also gradients of striatal distribution in primates (Graybiel and Moratalla, 1989; Hall et al., 1994; Madras and Kaufman, 1994; Piggott et al., 1999; Letchworth et al., 2001) as well as in rodents (Graybiel, 1990; Rivera et al., 2002). Such compartmental and graded distributions also characterize serotonin-related proteins (Graybiel, 1990; Waeber and Palacios, 1994) and a large range of other molecules, including neuropeptides (Graybiel, 1990; Hurd and Herkenham, 1995; Jakab et al., 1996) and second messenger molecules (Fotuhi et al., 1993; Garcia et al., 1993; Kawasaki et al., 1998; Pierret et al., 2002). D1-class dopamine receptor binding sites and dynorphin and its mRNA exhibit increased striosome-predominant expression patterns in animals and humans exposed repeatedly to cocaine and demonstrate dorsoventral gradients of distribution within the caudate-putamen complex (Hurd and Herkenham, 1993; Mathieu-Kia and Besson, 1998; Moore et al., 1998a,b; Fagergren et al., 2003). Fos-related proteins themselves have also been shown to have striosome-enriched expression patterns in the primate striatum in response to acute amphetamine treatment (Asin et al., 1996). Interestingly, when abnormalities in dopaminergic or cholinergic function are introduced experimentally in rodents, the link between striosome predominance and behavioral stereotypy can be broken (Saka et al., 2002; Glickstein and Schmauss, 2004). These findings suggest that the relationship between compartmental expression patterns and repetitive behaviors does indeed involve these striosome-enriched neurotransmitter systems.

Our findings also emphasize that neurons of the matrix were strongly activated in relation to challenge-induced stereotypy, particularly matrix neurons in the dorsolateral putamen. This finding is in good accord with evidence that the matrix is interconnected with sensorimotor and associative cortex and contains most neurons of origin of the direct and indirect pathways. Activation of such neurons may control the particular motor qualities of the stereotypic motifs elicited on challenge, a suggestion also in accord with the observation (Tremblay et al., 2003) that focal stimulation of the external pallidum can induce persistent stereotypies. We did not analyze responses to drug challenges given after different time points after the post-treatment period of abstinence, but in rodents it is known that repeated cocaine treatments downregulate early-gene inducibility in the striatum, after which inducibility recovers during subsequent drug-free periods (Hope et al., 1992; Persico et al., 1993; Steiner and Gerfen, 1993; Ennulat et al., 1994; Moratalla et al., 1996; Todtenkopf et al., 2002). If these dynamics hold in primates, as our experiments suggest, the dorsal zone of strong matrix and striosome labeling could represent the last region in a gradient of downregulation producing striosomal predominance moving from ventral to dorsal or the first region to recover balanced striosome-matrix activation in a reverse gradient of upregulation.

Finding a high correlation in the primate between striosomepredominant gene expression and stimulant-induced stereotypy suggests a remarkable conservation of basal ganglia activity patterns related to repetitive behaviors, extending at least from rodent to primate (Graybiel et al., 2000). Functional imaging stud- ies in humans have not yet been able to resolve striosomes, but a striosome-predominant pattern of dynorphin mRNA was noted in the striatum of cocaine abusers postmortem (Hurd and Herkenham, 1993), and this pattern was obvious in the putamen. It is possible, then, that the differential compartmental activation that we report here is a neural pattern that extends to the human brain, in which striosomes are highly developed (Graybiel and Ragsdale, 1978; Holt et al., 1997).

Two lines of evidence are of special interest in assessing this possibility. First, striosomes in the anterior parts of the caudate nucleus and ventral putamen receive preferential input from caudal orbitofrontal and anterior cingulate-medial prefrontal cortical regions (Donoghue and Herkenham, 1986; Ragsdale and Graybiel, 1990; Eblen and Graybiel, 1995; Ferry et al., 2000). Both orbitofrontal and anterior cingulate areas have been implicated in reward-related behavior, action selection, conflict monitoring, and the initiation or postponing of action (Paus, 2001). These cortical regions also exhibit metabolic dysregulation in human substance abusers (Goldstein and Volkow, 2002) and persons suffering from obsessive-compulsive disorder (Breiter et al., 1996; Graybiel and Rauch, 2000). The striosome-enriched activation patterns that we observed could represent differential strengthening of corticostriatal inputs from these cortical areas relative to others. Details of topography, however, need to be assessed, given the complexity of these cortical regions and the potential gradient of effects suggested by the dorsal caudoputamental labeling in monkeys of the chronic cocaine group. The second striking feature is that striosomes project to the region of the substantia nigra pars compacta (Gerfen, 1985; JiménezCastellanos and Graybiel, 1989). These anatomical patterns suggest that striosomes could constitute a negative feedback mechanism to control the functions of nigral neurons in the pars compacta (Steiner and Gerfen, 1998; Capper-Loup et al., 2002). If so, differential activation of orbitofrontal-anterior cingulatestriosome-nigral pathways could exacerbate repetitive actions by damping a nigral reinforcement signal returned to the striatum. The differential activation of striosomes could also serve as a homeostatic mechanism to compensate for overactivity of dopaminergic function such as that produced by cocaine. Such dysregulation, which appears to be a feature of psychostimulantinduced stereotypies, could contribute to the tics, stereotypies, and repetitive postural shifts exhibited in a range of obsessivecompulsive spectrum disorders.

\section{References}

Asin KE, Wirtshafter D, Nikkel A (1996) Amphetamine induces Fos-like immunoreactivity in the striatum of primates. Brain Res 719:138-142.

Badiani A, Oates MM, Day HE, Watson SJ, Akil H, Robinson TE (1998) Amphetamine-induced behavior, dopamine release, and c-fos mRNA expression: modulation by environmental novelty. J Neurosci 18: 10579-10593.

Baldessarini RJ (1972) Symposium: behavior modification by drugs. I. Pharmacology of the amphetamines. Pediatrics 49:694-701.

Bibb JA, Chen J, Taylor JR, Svenningsson P, Nishi A, Snyder GL, Yan Z, Sagawa ZK, Ouimet CC, Nairn AC, Nestler EJ, Greengard P (2001) Effects of chronic exposure to cocaine are regulated by the neuronal protein Cdk5. Nature 410:376-380.

Breiter HC, Rauch SL, Kwong KK, Baker JR, Weisskoff RM, Kennedy DN, Kendrick AD, Davis TL, Jiang A, Cohen MS, Stern CE, Belliveau JW, Baer L, O’Sullivan RL, Savage CR, Jenike MA, Rosen BR (1996) Functional magnetic resonance imaging of symptom provocation in obsessivecompulsive disorder. Arch Gen Psychiatry 53:595-606.

Canales JJ, Graybiel AM (2000) A measure of striatal function predicts motor stereotypy. Nat Neurosci 3:377-383.

Capper-Loup C, Canales JJ, Kadaba N, Graybiel AM (2002) Concurrent activation of dopamine $\mathrm{D}_{1}$ and $\mathrm{D}_{2}$ receptors is required to evoke neural 
and behavioral phenotypes of cocaine sensitization. J Neurosci 22:6218-6227.

Castner SA, Goldman-Rakic PS (1999) Long-lasting psychotomimetic consequences of repeated low-dose amphetamine exposure in rhesus monkeys. Neuropsychopharmacology 20:10-28.

Donoghue JP, Herkenham M (1986) Neostriatal projections from individual cortical fields conform to histochemically distinct striatal compartments in the rat. Brain Res 365:397-403.

Eblen F, Graybiel AM (1995) Highly restricted origin of prefrontal cortical inputs to striosomes in the macaque monkey. J Neurosci 15:5999-6013.

Ennulat DJ, Babb S, Cohen BM (1994) Persistent reduction of immediate early-gene mRNA in rat forebrain following single or multiple doses of cocaine. Mol Brain Res 26:106-112.

Fagergren P, Smith HR, Daunais JB, Nader MA, Porrino LJ, Hurd YL (2003) Temporal upregulation of prodynorphin mRNA in the primate striatum after cocaine self-administration. Eur J Neurosci 17:2212-2218.

Farfel GM, Kleven MS, Woolverton WL, Seiden LS, Perry BD (1992) Effects of repeated injections of cocaine on catecholamine receptor binding sites, dopamine transporter binding sites and behavior in rhesus monkey. Brain Res 578:235-243.

Ferry AT, Ongur D, An X, Price JL (2000) Prefrontal cortical projections to the striatum in macaque monkeys: evidence for an organization related to prefrontal networks. J Comp Neurol 425:447-470.

Fotuhi M, Dawson TM, Sharp AH, Martin LJ, Graybiel AM, Snyder SH (1993) Phosphoinositide second messenger system is enriched in striosomes: immunohistochemical demonstration of inositol 1,4,5triphosphate receptors and phospholipase $\mathrm{C} \beta$ and $\gamma$ in primate basal ganglia. J Neurosci 13:3300-3308.

Garcia MM, Cusick CG, Harlan RE (1993) Protein kinase C-delta in rat brain: association with sensory neuronal hierarchies. J Comp Neurol 331:375-388.

Gawin FH, Khalsa-Denison ME (1996) Is craving mood-driven or selfpropelled? Sensitization and "street" stimulant addiction. NIDA Res Monogr 163:224-250.

Gerfen CR (1985) The neostriatal mosaic. I. Compartmental organization of projections from the striatum to the substantia nigra in the rat. J Comp Neurol 236:454-476.

Glickstein SB, Schmauss C (2004) Focused motor stereotypies do not require enhanced activation of neurons in striosomes. J Comp Neurol 469:227-238.

Goldstein RZ, Volkow ND (2002) Drug addiction and its underlying neurobiological basis: neuroimaging evidence for the involvement of the frontal cortex. Am J Psychiatry 159:1642-1652.

Graybiel AM (1990) Neurotransmitters and neuromodulators in the basal ganglia. Trends Neurosci 13:244-254.

Graybiel AM, Chesselet MF (1984) Compartmental distribution of striatal cell bodies expressing [Met] enkephalin-like immunoreactivity. Proc Natl Acad Sci USA 81:7980-7984.

Graybiel AM, Moratalla R (1989) Dopamine uptake sites in the striatum are distributed differentially in striosome and matrix compartments. Proc Natl Acad Sci USA 86:9020-9024.

Graybiel AM, Ragsdale Jr CW (1978) Histochemically distinct compartments in the striatum of human, monkey, and cat demonstrated by acetylthiocholinesterase staining. Proc Natl Acad Sci USA 75:5723-5726.

Graybiel AM, Rauch SL (2000) Toward a neurobiology of obsessivecompulsive disorder. Neuron 28:343-347.

Graybiel AM, Canales JJ, Capper-Loup C (2000) Levodopa-induced dyskinesias and dopamine-dependent stereotypies: a new hypothesis. Trends Neurosci 23:S71-S77.

Haber S, Barchas PR, Barchas JD (1981) A primate analogue of amphetamine-induced behaviors in humans. Biol Psychiatry 16:181-196.

Hall H, Sedvall G, Magnusson O, Kopp J, Halldin C, Farde L (1994) Distribution of D1- and D2-dopamine receptors, and dopamine and its metabolites in the human brain. Neuropsychopharmacology 11:245-256.

Holt DJ, Graybiel AM, Saper CB (1997) Neurochemical architecture of the human striatum. J Comp Neurol 384:1-25.

Hope B, Kosofsky B, Hyman SE, Nestler EJ (1992) Regulation of immediate early-gene expression and AP-1 binding in the rat nucleus accumbens by chronic cocaine. Proc Natl Acad Sci USA 88:5764-5768.

Hurd YL, Herkenham M (1993) Molecular alterations in the neostriatum of human cocaine addicts. Synapse 13:357-369.

Hurd YL, Herkenham M (1995) The human neostriatum shows compart- mentalization of neuropeptide gene expression in dorsal and ventral regions: an in situ hybridization histochemical analysis. Neuroscience 64:571-586.

Hurd YL, Svensson P, Ponten M (1999) The role of dopamine, dynorphin, and CART systems in the ventral striatum and amygdala in cocaine abuse. Ann NY Acad Sci 877:499-506.

Jakab RL, Hazrati LN, Goldman-Rakic P (1996) Distribution and neurochemical character of substance P receptor (SPR)-immunoreactive striatal neurons of the macaque monkey: accumulation of SP fibers and SPR neurons and dendrites in "striocapsules" encircling striosomes. J Comp Neurol 369:137-149.

Jiménez-Castellanos J, Graybiel AM (1989) Compartmental origins of striatal efferent projections in the cat. Neuroscience 32:297-321.

Kalivas PW, Stewart J (1991) Dopamine transmission in the initiation and expression of drug- and stress-induced sensitization of motor activity. Brain Res Brain Res Rev 16:223-244.

Kalivas PW, Sorg BA, Hooks MS (1993) The pharmacology and neural circuitry of sensitization to psychostimulants. Behav Pharmacol 4:315-334.

Kawasaki H, Springett GM, Toki S, Canales JJ, Harlan P, Blumenstiel JP, Chen EJ, Bany IA, Mochizuki N, Ashbacher A, Matsuda M, Housman DE, Graybiel AM (1998) A Rap guanine nucleotide exchange factor enriched highly in the basal ganglia. Proc Natl Acad Sci USA 95:13278-13283.

LaHoste GJ, Yu J, Marshall JF (1993) Striatal Fos expression is indicative of dopamine D1/D2 synergism and receptor supersensitivity. Proc Natl Acad Sci USA 90:7451-7455.

Leckman JF (2002) Tourette's syndrome. Lancet 360:1577-1586.

Letchworth SR, Nader MA, Smith HR, Friedman DP, Porrino LJ (2001) Progression of changes in dopamine transporter binding site density as a result of cocaine self-administration in rhesus monkeys. J Neurosci 21:2799-2807.

Madras BK, Kaufman M (1994) Cocaine accumulates in dopamine-rich regions of primate brain after i.v. administration: comparison with mazindol distribution. Synapse 18:261-275.

Mathieu-Kia AM, Besson MJ (1998) Repeated administration of cocaine, nicotine and ethanol: effects on preprodynorphin, preprotachykinin A and preproenkephalin mRNA expression in the dorsal and the ventral striatum of the rat. Brain Res Mol Brain Res 54:141-151.

Miczek KA, Yoshimura H (1982) Disruption of primate social behavior by D-amphetamine and cocaine: differential antagonism by antipsychotics. Psychopharmacology 76:163-171.

Mink JW (2001) Basal ganglia dysfunction in Tourette's syndrome: a new hypothesis. Pediatr Neurol 25:190-198.

Moore RJ, Vinsant SL, Nader MA, Porrino LJ, Friedman DP (1998a) Effect of cocaine self-administration on striatal dopamine D1 receptors in rhesus monkeys. Synapse 28:1-9.

Moore RJ, Vinsant SL, Nader MA, Porrino LJ, Friedman DP (1998b) Effect of cocaine self-administration on dopamine $\mathrm{D} 2$ receptors in rhesus monkeys. Synapse 30:88-96.

Moratalla R, Vallejo M, Elibol B, Graybiel AM (1996) D1-class dopamine receptors influence cocaine-induced persistent expression of Fos-related proteins in striatum. NeuroReport 8:1-5.

Nestler EJ (2001) Molecular basis of long-term plasticity underlying addiction. Nat Rev Neurosci 2:119-128.

Nestler EJ, Kelz JB, Chen J (1999) DeltaFosB: a molecular mediator of longterm neural and behavioral plasticity. Brain Res 835:10-17.

Paus T (2001) Primate anterior cingulate cortex: where motor control, drive and cognition interface. Nat Rev Neurosci 2:417-424.

Persico AM, Smith SS, Uhl GR (1993) $\mathrm{D}_{2}$ receptor gene variants and substance abuse liability. Semin Neurosci 5:377.

Pierce RC, Kalivas PW (1997) A circuitry model of the expression of behavioral sensitization to amphetamine-like psychostimulants. Brain Res Brain Res Rev 25:192-216.

Pierret P, Mechawar N, Vallee A, Patel J, Priestley JV, Dunn RJ, Dower NA, Stone JC, Richardson PM (2002) Presence of Ras guanyl nucleotidereleasing protein in striosomes of the mature and developing rat. Neuroscience 111:83-94.

Piggott MA, Marshall EF, Thomas N, Lloyd S, Court JA, Jaros E, Costa D, Perry RH, Perry EK (1999) Dopaminergic activities in the human striatum: rostrocaudal gradients of uptake sites and of D1 and D2 but not of D3 receptor binding or dopamine. Neuroscience 90:433-445.

Porrino LJ, Lyons D, Miller MD, Smith HR, Friedman DP, Daunais JB, Nader MA (2002) Metabolic mapping of the effects of cocaine during the ini- 
tial phases of self-administration in the nonhuman primate. J Neurosci 22:7687-7694.

Post RM, Kopanda RT, Black KE (1976) Progressive effects of cocaine on behavior and central amine metabolism in rhesus monkeys: relationship to kindling and psychosis. Biol Psychiatry 11:403-419.

Ragsdale Jr CW, Graybiel AM (1990) A simple ordering of neocortical areas established by the compartmental organization of their striatal projections. Proc Natl Acad Sci USA 87:6196-6199.

Ridley RM (1994) The psychology of perseverative and stereotyped behaviour. Prog Neurobiol 44:221-231.

Rivera A, Cuellar B, Giron FJ, Grandy DK, de la Calle A, Moratalla R (2002) Dopamine D4 receptors are heterogeneously distributed in the striosomes/matrix compartments of the striatum. J Neurochem 80:219-229.

Robbins TW (1982) Stereotypies: addictions or fragmented actions? Bull Br Psychol Soc 35:297-300.

Robinson TE, Becker JB (1986) Enduring changes in brain and behavior produced by chronic amphetamine administration: a review and evaluation of animal models of amphetamine psychosis. Brain Res 396:157-198.

Rosenzweig-Lipson S, Hesterberg P, Bergman J (1994) Observational studies of dopamine D1 and D2 agonist in squirrel monkeys. Psychopharmacology 116:9-18.

Saka E, Iadarola M, Fitzgerald DJ, Graybiel AM (2002) Local circuit neurons in the striatum regulate neural and behavioral responses to dopaminergic stimulation. Proc Natl Acad Sci USA 99:9004-9009.

Sams-Dodd F, Newman JD (1997) Effects of administration regime on the psychotomimetic properties of D-amphetamine in the squirrel monkey (Saimiri sciureus). Pharmacol Biochem Behav 56:471-480.

Scraggs PR, Ridley RM (1978) Behavioural effects of amphetamine in a small primate: relative potencies of the D- and L-isomers. Psychopharmacology (Berl) 59:243-245.

Segal DS, Weinberger SB, Cahill J, McCunney SJ (1980) Multiple daily amphetamine administration: behavioral and neurochemical alterations. Science 207:905-907.

Steiner H, Gerfen CR (1993) Cocaine-induced c-fos messenger RNA is inversely related to dynorphin expression in striatum. J Neurosci 13:5066-5081.

Steiner H, Gerfen CR (1998) Role of dynorphin and enkephalin in the regulation of striatal output pathways and behavior. Exp Brain Res 123:60-76.

Todtenkopf MS, Mihalakopoulos A, Stellar JR (2002) Withdrawal duration differentially affects c-fos expression in the medial prefrontal cortex and discrete subregions of the nucleus accumbens in cocaine-sensitized rats. Neuroscience 114:1061-1069.

Tremblay L, Grabli D, McCairn K, Jan C, Hirsch E, Feger J, Francois C (2003) A monkey model of Tourette's syndrome: induction of hyperactivity disorder with attention deficit (HD/AD) and stereotypy by microinjections of bicuculline in the external segment of globus pallidus. Soc Neurosci Abstr 29:663.7.

Waeber C, Palacios JM (1994) Binding sites for 5-hydroxytryptamine-2 receptor agonists are predominantly located in striosomes in the human basal ganglia. Mol Brain Res 24:199-209.

Walters JR, Bergstrom DA, Carlson JH, Chase TN, Braun AR (1987) D1 dopamine receptor activation required for postsynaptic expression of D2 agonist effects. Science 236:719-722.

Willuhn I, Sun W, Steiner H (2003) Topography of cocaine-induced gene regulation in the rat striatum: relationship to cortical inputs and role of behavioural context. Eur J Neurosci 17:1053-1066. 